\title{
Broad Ligament Serous Adenofibroma
}

National Cancer Institute

\section{Source}

National Cancer Institute. Broad Ligament Serous Adenofibroma. NCI Thesaurus. Code C126478.

A rare serous adenofibroma arising from the broad ligament. 